\title{
BMJ Open Prognostic factors for relapse in patients with clinical stage I testicular cancer: protocol for a Danish nationwide cohort study
}

Thomas Wagner (10 , 1,2 Birgitte Grønkær Toft, ${ }^{2}$ Birte Engvad, ${ }^{3}$ Jakob Lauritsen, ${ }^{1}$ Michael Kreiberg, ${ }^{1}$ Mikkel Bandak, ${ }^{1}$ Josephine Rosenvilde, ${ }^{1}$ Ib Jarle Christensen, ${ }^{4}$ Anette Pedersen Pilt, ${ }^{5}$ Daniel Berney, ${ }^{6}$ Gedske Daugaard ${ }^{1}$

To cite: Wagner T, Toft BG, Engvad B, et al. Prognostic factors for relapse in patients with clinical stage I testicular cancer: protocol for a Danish nationwide cohort study. BMJ Open 2019;9:e033713. doi:10.1136/ bmjopen-2019-033713

- Prepublication history for this paper is available online. To view these files, please visit the journal online (http://dx.doi org/10.1136/bmjopen-2019033713).

$\mathrm{DB}$ and $\mathrm{GD}$ are joint senior authors.

Received 18 August 2019 Revised 20 September 2019 Accepted 25 September 2019

D Check for updates

(c) Author(s) (or their employer(s)) 2019. Re-use permitted under CC BY-NC. No commercial re-use. See rights and permissions. Published by BMJ.

For numbered affiliations see end of article.

Correspondence to Thomas Wagner; thomas.wagner.nielsen@ regionh.dk

\section{ABSTRACT}

Introduction Approximately one-fourth of patients with clinical stage I testicular germ cell cancer will relapse within 5 years of follow-up. Certain histopathological features in the primary tumour have been associated with an increased risk of relapse. The available evidence on the prognostic value of the risk factors, however, is hampered by heterogeneity of the study populations included and variable reporting of the histopathological features. The aim of this study is to identify pathological risk factors for relapse in an unselected large nationwide cohort of patients with stage I disease.

Methods and analysis All incident cases of stage I testicular germ cell cancer diagnosed in Denmark between 2013 and 2018 will be identified using the nationwide prospective Danish Testicular Cancer (DaTeCa) database. Archived microscopic slides from the orchiectomy specimens will be retrieved through linkage to the Danish Pathology Data Bank and reviewed blinded to the clinical outcome. The DaTeCa database includes 960 stage I seminoma patients with expected 185 relapses and 480 patients with stage I non-seminoma with expected 150 relapses. A minimum follow-up period of 3 years of all patients will be ensured. Predefined prognostic variables will be investigated with regard to relapse in univariable and multivariable analysis using the Cox proportional hazards model.

Ethics and dissemination This study protocol has been approved by the Regional Ethics Committee (Region Zealand, Denmark) and the Danish Data Protection Agency. All data will be managed confidentially according to legislation. Study results will be presented at international conferences and published in peer-review journals.

\section{INTRODUCTION}

Approximately $70 \%$ of all incident cases of testicular germ cell cancer (TGCC) are diagnosed as clinical stage I (CS I) disease. ${ }^{12}$ Using a surveillance strategy, around one-fourth of the patients will relapse within 5 years of follow-up. ${ }^{1} 4$ Today, cure rates approach $100 \%$ irrespective of the postorchiectomy strategy employed, as chemotherapy and/
Strengths and limitations of this study

- A population-based, nationwide cohort of unselected patients with clinical stage I testicular cancer following a surveillance programme where none receive adjuvant treatment.

- Clinical data are retrieved from the prospective Danish Testicular Cancer database, with the possibility of linking data from different registries enabling detection of all relapses.

- A uniform central pathology review of all the included orchiectomy specimens blinded to the clinical outcome.

- Predefined analyses according to published protocol.

A few patients will relapse after 3 years of follow-up.

or radiotherapy cures nearly all patients with relapse. ${ }^{1-3} 5-8$ Treatment, however, is associated with long-term late-effects such as increased risk of secondary malignancy and cardiovascular disease. ${ }^{9}$ Minimising treatment-related morbidity in these young patients with life expectancy comparable to an age-matched noncancerous male population is important. ${ }^{10}$ Accurate risk prediction of relapse is crucial to clarify the optimal treatment strategy in terms of surveillance in low-risk groups and adjuvant treatment in high-risk groups. At present, the histopathological risk factors in the primary tumour employed to define high-risk group in CS I patients are not very well founded and do not constitute a good basis for decision on adjuvant treatment. Existing studies are often hampered by heterogeneous study populations, ${ }^{71-16}$ substantial amount of missing data, ${ }^{1}{ }^{3} 41317$ limited statistical power, ${ }^{13} 1819$ lack of central pathology review ${ }^{137131719}$ and with potential variable reporting of the histopathological risk factors. ${ }^{20-24}$ Further, the prognostic power of the risk factors is low. 
In seminoma, a clear correlation between increasing tumour size and risk of relapse has been reported. ${ }^{34131617}$ A cut-off value of $4 \mathrm{~cm}$ is the most frequently studied, but evidence to justify this cut-off is lacking. ${ }^{13}{ }^{14}$ Even in a 'high-risk setting' (tumours $6 \mathrm{~cm}$ or larger) adjuvant radiotherapy led to overtreatment in two-thirds of the patients. ${ }^{25}$ Conflicting results have been published concerning other risk factors, including lymphovascular invasion (LVI) and rete testis invasion (RTI), ${ }^{3} 413-172627$ likely caused by the methodological problems.

In non-seminoma, previous studies have shown that LVI is a risk factor for relapse. ${ }^{14719}$ Yet, its predictive value is debatable. A 5-year relapse risk of 50\% and 15\% in patients with and without LVI is often mentioned. ${ }^{5719}$ Other studies, however, report a relapse risk of $18 \%-40 \%$ in patients with LVI. ${ }^{1428}$ Further, the reported proportion of tumours with LVI vary considerably between $15 \%$ and $49 \%{ }^{1472930}$ The presence or percentage of embryonal carcinoma (EC) has been shown to increase the risk of relapse. ${ }^{14192931}$ However, whether the percentage of $\mathrm{EC}$ or just the presence of EC in the tumour is of equal importance is unclear.

Further characterisation of risk factors for relapse, such as local tumour spread into adjacent structures like rete testis, hilar soft tissue, epididymis and spermatic cord, is needed in both seminoma and non-seminoma. In addition, previous studies often investigate only a limited number of possible risk factors and rarely the combined risk of different risk factors.

\section{AIMS}

The aim of the present study is to identify pathological risk factors for relapse in an unselected nationwide cohort of patients with CS I disease all followed on a surveillance programme. In two separate cohorts (seminoma/nonseminoma), we aim to:

\section{Seminoma}

- Confirm tumour size as a risk factor for relapse as identified in previous studies.

- Clarify the prognostic value of RTI, epididymis invasion, tunica albuginea invasion, tunica vaginalis invasion, LVI and tumour necrosis with conflicting results in previous studies.

- Investigate hilar soft tissue invasion and spermatic cord invasion as potential risk factors for relapse.

- Investigate whether a combination of risk factors can identify patients at high risk of relapse.

\section{Non-seminoma}

- Confirm LVI as a risk factor for relapse as identified in previous studies.

- Clarify the prognostic value of RTI, epididymis invasion, tunica albuginea invasion, tunica vaginalis invasion, tumour size, tumour necrosis and the histologic tumour types (EC, yolk sac tumour, choriocarcinoma, seminoma and teratoma) with conflicting results in previous studies.

- Investigate hilar soft tissue invasion and spermatic cord invasion as potential risk factors for relapse.

- Investigate whether a combination of risk factors can identify patients at high risk of relapse.

Further, the prognostic value of the preorchiectomy levels of the serum tumour markers (STMs) $\alpha$-fetoprotein (AFP), $\beta$-human choriogonadotropin (hCG) and lactate dehydrogenase (LDH) will be investigated in seminoma/ non-seminoma, respectively.

\section{METHODS AND ANALYSIS}

\section{Study population and study design}

All males aged $\geq 15$ years in Denmark diagnosed with incident CS I TGCC between 1 January 2013 and 31 December 2018 are included in a nationwide, populationbased study divided into two separate cohorts:

Study cohort I: patients with CS I pure seminoma.

Study cohort II: patients with CS I non-seminoma.

Relapse is defined as either a confirmed tumour marker relapse (hCG, AFP) and/or radiological signs of relapse. The time point for relapse can be either increase in tumour marker or a positive CT scan depending on which comes first.

End of follow-up is planned on 31 December 2021 ensuring a minimum follow-up period of 3 years of all patients. For seminoma, $90 \%$ of the relapses occur within 3 years of follow-up, ${ }^{3}$ for non-seminoma, more than $90 \%$ of relapses occur within 2 years of follow-up. ${ }^{1}$

\section{Staging and follow-up}

All patients with TGCC are treated with inguinal orchiectomy followed by staging with STMs (AFP, hCG and LDH) and a CT scan of thorax and abdomen. CS I disease is defined as normal postoperative STMs, and no radiologic or clinical evidence of regional or distant metastatic disease. The orchiectomy procedures are carried out at local urological departments throughout Denmark with subsequent pathological examinations at 11 different pathological departments. Follow-up and treatment are harmonised in national multidisciplinary guidelines and carried out at three university hospitals responsible for this patient group. Patients with stage I disease are, regardless of pathological characteristics (pT1-4N0M0S0), followed by a uniform, national 5 -year surveillance programme. ${ }^{13}$ After 5 years of follow-up, survival and possible relapse can be followed through national registries, as outlined below.

\section{Data sources}

Data are obtained from the prospective Danish Testicular Cancer (DaTeCa) database ${ }^{32}$ and linkage of the DaTeCa database to the following national registries: the Danish Pathology Registry (DPR) ${ }^{3334}$ the Danish National Patient Registry (DNPR) ${ }^{35}$ and the Danish Civil Registration System (CRS) ${ }^{36}$ as specified in table 1 . Individual-level 
Table 1 Overview of the variables and the data sources in the prospective DaTeCa database used for the study

\begin{tabular}{|c|c|c|}
\hline Variables & Sources & Specification \\
\hline $\begin{array}{l}\text { Diagnosis of incident } \\
\text { TGCC }\end{array}$ & $\begin{array}{l}\text { The Danish Pathology Registry } \\
\text { and/or } \\
\text { The National Patient Registry }\end{array}$ & $\begin{array}{l}\text { Patients aged } \geq 15 \text { years and } \\
\text { SNOMED codes (Danish version): } \\
\text { T780* (Testis) and one of the following M-codes: } \\
\text { M906×3 }{ }^{\text {a }} \text { (seminoma; seminoma with syncytiotrophoblast) } \\
\text { M907×3 (embryonal carcinoma; yolk sac tumour) } \\
\text { M908×3 (teratoma; teratoma with somatic malignancy) } \\
\text { M910×3 (choriocarcinoma) } \\
\text { M90800 (mature teratoma) } \\
\text { M90801 (solid teratoma) } \\
\text { a excluding } \\
\text { M90633 (spermatocytic tumour) } \\
\text { M90663 (spermatocytic tumour with sarcoma) } \\
\text { ICD-10 diagnosis codes: } \\
\text { C62* (malignant neoplasm of testis) excluding } \\
\text { C62.9X (local recurrence from testicular cancer) }\end{array}$ \\
\hline Relapse & $\begin{array}{l}\text { Clinical registered data and/or } \\
\text { The Danish Pathology Registry } \\
\text { and/or } \\
\text { The National Patient Registry }\end{array}$ & $\begin{array}{l}\text { SNOMED codes (Danish version): } \\
\text { Any T code and one of the following M-codes: } \\
\text { M906x6 } 6^{\text {b }} \text { (metastasis, seminoma; metastasis, seminoma with } \\
\text { syncytiotrophoblast) } \\
\text { M907×6 (metastasis, embryonal carcinoma; metastasis, yolk sac } \\
\text { tumour) } \\
\text { M908×6 (metastasis, teratoma; metastasis, teratoma with somatic } \\
\text { malignancy) } \\
\text { M910×6 (metastasis, choriocarcinoma) } \\
\text { M90806 (metastasis, mature teratoma) } \\
\text { M90806 (metastasis, solid teratoma) } \\
\text { b excluding } \\
\text { M90636 (metastasis, spermatocytic tumour) } \\
\text { M90666 (metastasis, spermatocytic tumour with sarcoma) } \\
\text { and/or } \\
\text { AFF4630 (metastasis with primary tumour in testis) } \\
\text { ICD-10 diagnosis codes: } \\
\text { C62* (Malignant neoplasm of testis) and } \\
\text { SKS treatment codes: } \\
\text { BWG (radiation therapy) and/or } \\
\text { BWHA (cytostatic treatment) }\end{array}$ \\
\hline Vital status & $\begin{array}{l}\text { The Danish Civil Registration } \\
\text { System }\end{array}$ & Dead, alive or emigrated \\
\hline
\end{tabular}

ÆE, etiology; AFP, $\alpha$-fetoprotein; CS I, clinical stage I; DaTeCa database, Danish Testicular Cancer database; F, function; hCG, $\beta$-human choriogonadotropin; ICD-10, International Classification of Disease, tenth revision; LDH, lactate dehydrogenase; M, morphology; SKS (in Danish), Sundhedsvæsenets Klassifikations System; SNOMED, Systematised Nomenclature of Medicine; STMs, serum tumour markers; T, topography; TGCC, testicular germ cell cancer.

linkage of data is possible due to a unique civil personal 10-digit registration number (Danish civil registration number, CPR), assigned to all Danish citizens at birth or immigration, which is recorded along with administrative and medical information in registries and databases. ${ }^{36} 37$

\section{The prospective DaTeCa database}

The nationwide clinical database holds information of all incident germ cell cancers (GCCs) in males aged $\geq 15$ years of both gonadal and extragonadal origin in Denmark from 2013 onward. ${ }^{32}$ The database contains prospectively collected clinical data registered by the treating physicians at the oncological departments by using standardised case report forms, as previously described, ${ }^{32}$ including information on clinical stage, relapse data and preorchiectomy values of STMs (AFP, hCG and LDH) used for this study. The database is linked to the DPR and the DNPR to ensure completeness of the identification of all incident TGCC cases as well as of the reporting to the database, table 1 . In total, $98 \%-100 \%$ of all newly diagnosed patients identified in the DPR and DNPR have an online registration form filled out during the study period 2013-2018. ${ }^{38}$ The high completeness is possible 
as patients identified in the registries but not registered from the departments can be localised and enquiries sent to the departments. Further, safeguarding against missing information on critical data, such as relapse, is also ensured by the crosschecking, table 1 .

\section{The Danish Pathology Registry}

The DPR receives data from the Danish Pathology Data Bank (DPDB) and holds information on all pathological specimens analysed in Denmark since 1997. ${ }^{33} 34$ All Danish pathology departments have electronically recorded standard data on biological specimens according to national guidelines for uniform registration. Registration is performed by the investigating pathologist and is based on the Danish version of the Systemised Nomenclature of Medicine (SNOMED) codes. ${ }^{33}$

\section{The Danish National Patient Registry}

In the DNPR, all hospital contacts, including outpatient visits, are registered.$^{35}$ Information regarding hospital admission, such as date of admission and discharge and diagnosis codes at discharge, classified according to International Classification of Disease, tenth revision (ICD-10), are registered.$^{35}$ In addition, procedure codes such as chemotherapy and radiotherapy codes are registered according to the Healthcare Classification System (Danish, Sundhedsvæsenets Klassifikations System). ${ }^{39} 40$

\section{The Danish CRS}

The CRS holds information on vital status and migration which is updated daily. ${ }^{36}$

\section{Data construction and collection}

Figure 1 summarises the process of defining the cohort and collection of the orchiectomy specimens. All patients with CS I disease identified in the prospective DaTeCa database will initially be coupled to the Danish 'Vævsanvendelsesregister'/Register of Human Tissue Utilisation, ${ }^{34}$ and patients who have registered that their tissue cannot be used for scientific purposes will be excluded. Patients with GCC of extragonadal origin, synchronous or metachronous TGCC are also excluded. By linkage to the DPDB, the identification and location of the archived histopathological slides (H\&E stained slides (HE) and immunohistochemical (IHC) stained slides) from the orchiectomy specimens in the various pathology departments throughout Denmark are obtained, as well as information from the original pathology reports concerning

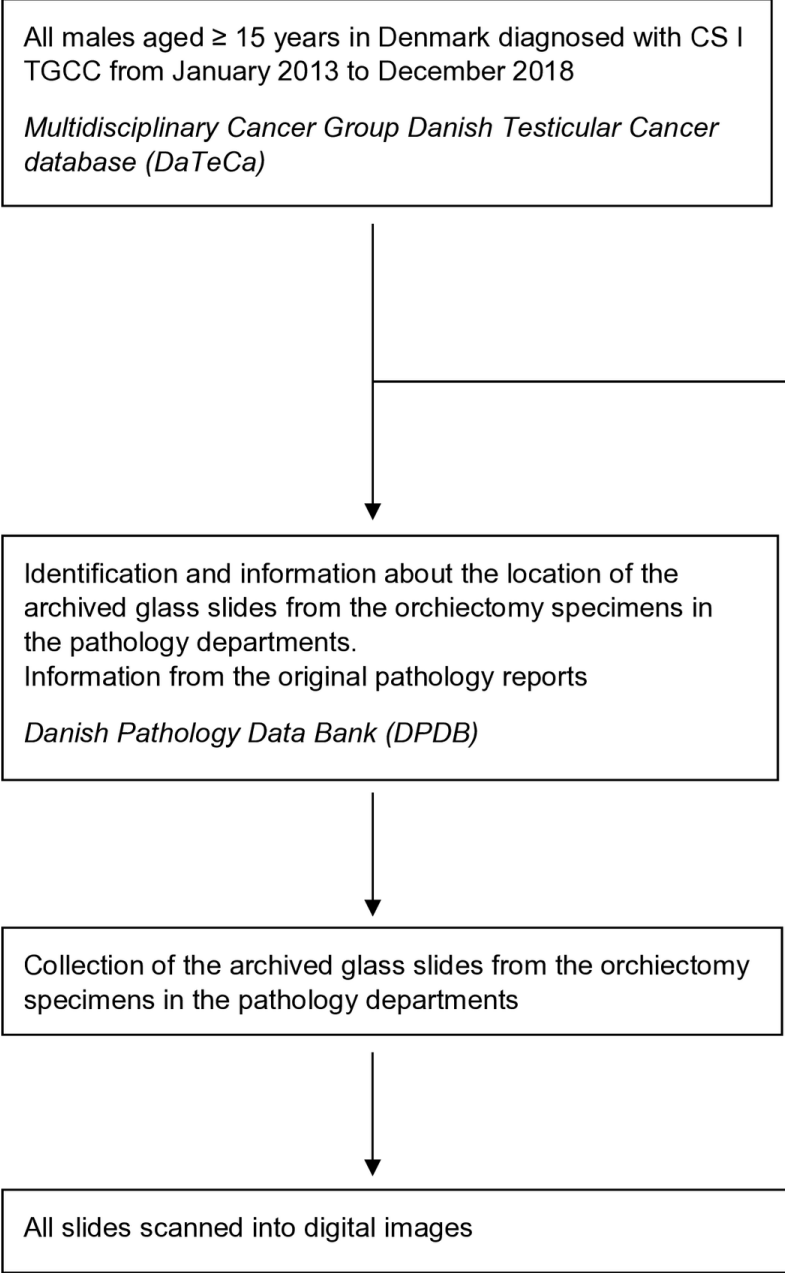

Figure 1 Flowchart outlining the definition of the study population and data collection. CS I, clinical stage I; GCC, germ cell cancer; TGCC, testicular germ cell cancer. 
gross and microscopic descriptions and diagnosis. The length of time for which the glass slides from the specimens are stored in the archives varies by pathology department (usually between 5 and 10 years). If any slides are discarded or missing, the corresponding formalin-fixed, paraffin-embedded (FFPE) blocks will be collected and new HE slides will be made. As Danish pathology departments store paraffin blocks permanently, ${ }^{33}$ we expect to be able to retrieve all FFPE blocks from all the patients, if relevant. All slides will be scanned into digital images.

\section{Data analyses}

Microscopic slides from the orchiectomy specimens and information from the original pathology reports will be reviewed by the same pathologist (TW) without knowledge of the clinical outcome. The most recent recommendations from the International Society of Urological Pathologists (ISUP) ${ }^{41}$ and the International Collaboration on Cancer Reporting (ICCR) ${ }^{42}$ regarding the reporting of microscopic features in testicular germ cell tumours with clear definitions of various parameters will be used. The following gross and microscopic parameters will be recorded, as defined in table 2: tumour size, tumour necrosis, LVI and tumour involvement of tunica albuginea, tunica vaginalis, rete testis, hilar soft tissue, epididymis and spermatic cord. If present in nonseminoma tumours, the histologic tumour type showing the stated feature will be recorded. Further, in nonseminoma tumours, the presence and absence of each histologic tumour type with corresponding percentages as a continued variable will be recorded. All cases will be reclassified in accordance with the WHO 2016 histological classification. ${ }^{43}$ In case of diagnostic uncertainty, the slides will be reviewed by two additional pathologists (BGT and DB) to reach a consensus. If during the review it is deemed necessary to perform IHC staining (OCT3/4, CD30, CD117, D240, Glypican3, AFP, hCG, CD31 and CD34 according to the ISUP recommendations) ${ }^{44}$ or molecular testing for chromosome $12 \mathrm{p}$ amplification by fluorescence in situ hybridisation (FISH) and/or PCR, for differential diagnostic purposes, the relevant tissue block will be collected. After completing the revision, the pathological features will be tested with regard to clinical outcome (see the 'Statistical analysis' section). National guidelines on handling and sampling of orchiectomy specimens have been standardised in Denmark for many years, ${ }^{45}$ and is in accordance with international recommendations. ${ }^{42}$ As such, adequate sampling and thereby a minimum of missing values is expected.

\section{Statistical analysis}

The aim of this study is to investigate the association of clinical-pathological covariates as explanatory variables to the primary outcome, that is, time to relapse. Patients without a relapse will be censored at the final date or the date of death or emigration if occurring prior to the final date. The explanatory covariates are listed in table 2. Descriptive statistics will be presented in tables for categorical variables and by the median with minimum, maximum as well as first and third quartiles for continuous variables stratified by seminoma/nonseminoma. The primary analysis will be performed using the Cox proportional hazards model, analysed separately for seminoma and non-seminoma. Explanatory covariates will be scored as categorical variables if discrete, and as continuous variable if appropriate. For the latter, possible transformation will be utilised to achieve the correct functional form, the most likely transformation is the $\log$ of the explanatory covariate. Model assessment will be done employing martingale residuals to confirm the proportional hazards assumption and the functional form if applicable. If the assumption of proportional hazards is violated alternative parameterisation will be done using time-dependent Cox models. In the event of missing explanatory variables, multiple imputation will be performed with 25 imputations. ${ }^{46} 47$ Significant combinations of explanatory covariates will be identified using backwards selection validated using 10-fold cross validation. ${ }^{48}$ The results will be presented as estimates of hazard ratio (HR) with $95 \%$ confidence limits and cumulative incidence rates using the Nelson-Aalen estimator. The plausible risk factors for relapse: scrotum invasion and tumour in the spermatic cord margin, will not be included in the primary analyses in case of (and as expected) few events $(<10)$; neither will tunica vaginalis invasion in case of few events $(<10)$. Statistical calculations will be done using SAS and R, The R Foundation for Statistical Computing Platform.

\section{Sample size and power considerations}

Study cohort 1: With approximately 160 incident cases of CS I seminoma per year in Denmark, ${ }^{40}$ the cohort is estimated to constitute approximately 960 patients and 185 incident relapses. Study cohort II: With approximately 80 incident cases of CS I non-seminoma per year in Denmark ${ }^{40}$ the cohort is estimated to constitute approximately 480 patients and 150 incident relapses. Assuming a 5\% significance level (two sided), there will be $80 \%$ power to detect a HR of a continuous covariate of 1.21 or greater (or 0.83 or lower) in a multivariable Cox regression model with $\mathrm{r}^{2}=0.2$ regressing the covariate of interest on the remaining covariates and a $\mathrm{SD}=1.2$ in study cohort 1 , and 1.24 (or 0.81) in study cohort $2 .{ }^{49}$ For a binary covariate, the estimated power to detect a HR greater than 1.6 (or 0.63 or lower) is $80 \%$ if the proportion of positives is $35 \%$ in study cohort 1 . If the proportion of positives is $15 \%$, then there is $80 \%$ power to detect a HR of 1.9. Similarly for study cohort 2, the HR that can be detected at $80 \%$ power are 1.7 and $2.0 .^{50}$ All analyses assume that $r^{2}=0.2$ between the covariate of interest and other explanatory covariates. Most clinically, relevant HR will likely be higher, and therefore this study has sufficient power to address the research questions posed. Calculations have been performed using 'Proc Power', SAS V.9.4 and package 'powerSurvEpi', R V.3.5.0. 
Table 2 Summary of the included possible risk factors and definitions

\begin{tabular}{|c|c|c|}
\hline Variable & Type & Definition \\
\hline $\begin{array}{l}\text { Demographical } \\
\text { Age }\end{array}$ & $\begin{array}{l}\text { Continuous } \\
\text { variable }\end{array}$ & Age at diagnosis, years \\
\hline$\frac{\text { Biochemical }}{\text { AFP }}$ & $\begin{array}{l}\text { Continuous } \\
\text { variable }\end{array}$ & Preorchiectomy level, IU/L \\
\hline hCG & $\begin{array}{l}\text { Continuous } \\
\text { variable }\end{array}$ & Preorchiectomy level, IU/L \\
\hline $\mathrm{LDH}$ & $\begin{array}{l}\text { Continuous } \\
\text { variable }\end{array}$ & Preorchiectomy level, U/L \\
\hline
\end{tabular}

$\begin{array}{ll}\frac{\text { Pathological }}{\text { Tumour size }} & \begin{array}{l}\text { Continuous } \\ \text { variable }\end{array}\end{array}$

Largest tumour diameter, $\mathrm{mm}$

In case of multifocality: (a) maximal diameter of the largest focus and (b) 'total tumour diameter', calculated as the sum of the maximal diameter in each lesion. Multifocality is defined by coexistence of independent tumoural foci; largely depending of the macroscopic description in the original pathology report. However, if section described as taken from normal parenchyma macroscopically, but consists of tumour microscopically, this will be counted as a tumoural focus. In order to be calculated as a tumour focus, the lesion must at least measure $1 \mathrm{~mm}$ in diameter.

A focus of regression will be calculated as a tumoural focus as well, if independent and measures $1 \mathrm{~mm}$ or more in largest diameter.

Areas of necrosis and fibrosis (regression) will be calculated in the maximal tumour diameter, if it is measured as part of the tumour in the gross description.

Pagetoid involvement
of the rete testis

Binary variable (present/absent)

\begin{tabular}{ll} 
Rete testis invasion & $\begin{array}{l}\text { Binary variable } \\
\text { (present/absent) }\end{array}$ \\
$\begin{array}{l}\text { Hilar soft tissue } \\
\text { invasion }\end{array}$ & $\begin{array}{l}\text { Binary variable } \\
\text { (present/absent) }\end{array}$ \\
\hline Epididymis invasion & $\begin{array}{l}\text { Binary variable } \\
\text { (present/absent) }\end{array}$ \\
\hline $\begin{array}{l}\text { Spermatic cord } \\
\text { invasion }\end{array}$ & $\begin{array}{l}\text { Binary variable } \\
\text { (present/absent) }\end{array}$
\end{tabular}

invasion

Extension into the rete testis epithelium of individual or groups of GCNIS cells.

Tumour cells in the stroma between rete tubular channels, or clear destruction of the testicular hilum.

Tumour extension into the soft tissue beyond the rete testis at the same plane of section as the testis parenchyma.

If epididymis is described without tumour involvement on the gross description, but (exceptionally) is not visualised in the section taken from the area, we will rely on the macroscopic description and state no involvement (unless we expect it to be involved from other sections taken).

Tumour extending grossly beyond the hilum, with the base of the cord defined as a section just superior to the head of caput epididymis, or tumour is adjacent to or surrounds the vas deferens.

Discontinuous involvement of the spermatic cord by vascular-lymphatic soft tissue invasion will be registered separately as a local metastasis.

$\begin{array}{ll}\begin{array}{l}\text { Tunica albuginea } \\ \text { invasion }\end{array} & \begin{array}{l}\text { Binary variable } \\ \text { (present/absent) }\end{array} \\ \begin{array}{l}\text { Tunica vaginalis } \\ \text { invasion }\end{array} & \begin{array}{l}\text { Binary variable } \\ \text { (present/absent) }\end{array} \\ \begin{array}{l}\text { Lymphovascular } \\ \text { invasion (LVI) }\end{array} & \begin{array}{l}\text { Binary variable } \\ \text { (present/absent) }\end{array}\end{array}$

Invasion of tumour into the fibrous layer immediately surrounding the testicular parenchyma.

Penetration of the mesothelium of the visceral layer of tunica vaginalis.

Cohesive cells often adherent to the wall of the vessel, located preferably in tunica albuginea or peritumoural location. Associated fibrin material further supports the presence of true LVI. Lack of obvious background artifactual deposition of tumour. The location of LVI in testis or/and spermatic cord will be registered separately, as will any soft tissue invasion in the spermatic cord through lymphovascular spaces. In cases where LVI is indeterminate from artefact/contamination, the LVI status wil be regarded as negative.

$\begin{array}{lll}\text { Tumour necrosis } & \begin{array}{l}\text { Continuous } \\ \text { variable }\end{array} & \text { The amount of tumour necrosis in percentage. }\end{array}$

\section{Spermatic cord margin Binary variable} involvement (present/absent)

Tumour subtype, non- Continuous seminoma variables
Tumour in section taken from the margin (excluding implantation artefact and tumour cells confined to the vascular spaces at the margin).

The amount of histologic tumour types in percentages: embryonal carcinoma seminoma yolk sac tumour choriocarcinoma teratoma.

If teratoma with somatic type malignancy: in addition, the type and diameter of the largest focus. 
Table 2 Continued

\begin{tabular}{lll}
\hline Variable & Type & Definition \\
\hline Scrotum invasion & $\begin{array}{l}\text { Binary variable } \\
\text { (present/absent) }\end{array}$ & $\begin{array}{l}\text { Tumour invades beyond the tunica vaginalis and spermatic fascia into soft tissue } \\
\text { or skin of the scrotum. }\end{array}$ \\
\hline
\end{tabular}

AFP, $\alpha$-fetoprotein; GCNIS, germ cell neoplasia in situ; hCG, $\beta$-human choriogonadotropin; LDH, lactate dehydrogenase; LVI, lymphovascular invasion.

\section{Patients and public involvement}

Involvement of all Danish CS I TGCC patients will be ensured through nationwide registries. Since the material used for evaluating pathological risk factor consists of slides for microscopy originally collected for diagnostic purposes, the patients are unable to participate and engage directly in the current study. Our data material is ideal for performing prognostic factor research in patients with CS I disease, and our aim is to clarify risk factors with significant influence on relapse. Thus, future CS I TGCC patients can make their decision about continued surveillance or adjuvant chemotherapy based on solid data. Potentially, our results will entail individual follow-up programmes based on risk of recurrence, which for some patients could imply less intense follow-up than we do today.

\section{DISCUSSION}

Accurate risk prediction of relapse is essential to avoid the potential serious long-term consequences of overtreatment in a large proportion of patients who are cured by orchiectomy alone. Solid data are missing to define patients with high risk of relapse, who would benefit from up-front adjuvant treatment. Based on prospectively collected clinical data and central pathology review of the orchiectomy specimens, the present population-based nationwide cohort study of adjuvant treatment-naïve CS I TGCC patients will provide solid evidence of pathological risk factors for relapse. The results of the present study have the potential to stratify patients into high- and lowrisk groups based on their risk of relapse. This stratification may lead to individualised follow-up programmes and treatment, with less morbidity and costs for the patients and health system.

This study has several strengths. First, it includes a nationwide consecutive cohort of truly unselected CS I disease patients. These patients, regardless of pathological characteristics and pathological stage (pT14N0M0S0), are following a surveillance programme without any adjuvant therapy. Second, all the included orchiectomy specimens go through a uniform central pathology review. Third, clinical data including relapse data are registered prospectively in the nationwide, clinical DaTeCa database. Fourth, individual-level linkage of data with several nationwide health registries enables us to detect all relapses. Finally, data are analysed according to a predefined analysis plan stated in the peer-reviewed published protocol.
There are some limitations to this study. As the initial examinations of the orchiectomy specimens have been performed in various pathology departments, there is a risk of inconsistent gross examination and sampling of the specimens. Thus, for example, the hilar region might be undersampled in some cases which can lead to missing values of the histopathological variables. However, as stated previously, national guidelines on handling and sampling of orchiectomy specimens have been standardised in Denmark for many years, and therefore, adequate sampling and thereby a minimum of missing values is expected. Another limitation is the limited follow-up time of the patients diagnosed at the end of the study period.

\section{Ethics and dissemination}

Neither active recruitment nor interventions of study participants will take place. Study results will be presented at international conferences and published in peer-review journals.

\section{Author affiliations}

${ }^{1}$ Department of Oncology, Copenhagen University Hospital, Rigshospitalet, Copenhagen, Denmark

${ }^{2}$ Department of Pathology, Copenhagen University Hospital, Rigshospitalet, Copenhagen, Denmark

${ }^{3}$ Department of Pathology, Odense University Hospital, Odense, Denmark

${ }^{4}$ Gastro Unit, Copenhagen University Hospital, Hvidovre, Denmark

${ }^{5}$ Department of Pathology, Zealand University Hospital, Roskilde, Denmark

${ }^{6}$ Department of Molecular Oncology, Barts Cancer Institute, Queen Mary University of London, London, UK

Contributors TW developed the conception and design of the study, obtained permissions and funding and drafted the study protocol. GD and BGT developed the conception and design of the study, obtained funding and provided critical revision of the study protocol. IJC was involved in the statistical design and provided critical revision of the study protocol. BE, JL, MK, MB, JR, APP and DB contributed to the conception and design of the study and provided critical revision of the study protocol. All authors read and approved the final manuscript.

Funding Thomas Wagner is funded by the Danish Cancer Society (grant number: R204-A12597). Daniel Berney is supported by Orchid. The study is supported in part by the Danish Cancer Research Foundation, the Preben and Anna Simonsen's Foundation and the Valdemar Beck's Foundation. The funding parties played no role in any part of the design, conduction, analysis plan or publication plan for this study. Competing interests None declared.

Patient consent for publication Not required.

Ethics approval This study protocol has been approved by the Regional Ethics Committee (Region Zealand, Denmark), approval number SJ-690, and the Danish Data Protection Agency, approval no. VD-2018-433.

Provenance and peer review Not commissioned; externally peer reviewed.

Open access This is an open access article distributed in accordance with the Creative Commons Attribution Non Commercial (CC BY-NC 4.0) license, which 
permits others to distribute, remix, adapt, build upon this work non-commercially, and license their derivative works on different terms, provided the original work is properly cited, appropriate credit is given, any changes made indicated, and the use is non-commercial. See: http://creativecommons.org/licenses/by-nc/4.0/.

\section{ORCID iD}

Thomas Wagner http://orcid.org/0000-0002-0256-0074

\section{REFERENCES}

1 Daugaard G, Gundgaard MG, Mortensen MS, et al. Surveillance for stage I nonseminoma testicular cancer: outcomes and long-term follow-up in a population-based cohort. JCO 2014;32:3817-23.

2 Nichols CR, Roth B, Albers P, et al. Active surveillance is the preferred approach to clinical stage I testicular cancer. JCO 2013;31:3490-3

3 Mortensen MS, Lauritsen J, Gundgaard MG, et al. A nationwide cohort study of stage I seminoma patients followed on a surveillance program. Eur Urol 2014;66:1172-8.

4 Nayan M, Jewett MAS, Hosni A, et al. Conditional risk of relapse in surveillance for clinical stage I testicular cancer. Eur Urol 2017;71:120-7.

5 Cohn-Cedermark G, Stahl O, Tandstad T, et al. Surveillance vs. adjuvant therapy of clinical stage I testicular tumors - a review and the SWENOTECA experience. Andrology 2015;3:102-10.

6 Sturgeon JF, Moore MJ, Kakiashvili DM, et al. Non-Risk-Adapted Surveillance in Clinical Stage I Nonseminomatous Germ Cell Tumors: The Princess Margaret Hospital's Experience. Eur Urol 2011;59:556-62.

7 Kollmannsberger C, Tandstad T, Bedard PL, et al. Patterns of relapse in patients with clinical stage I testicular cancer managed with active surveillance. JCO 2015;33:51-7.

8 Pierorazio PM, Albers P, Black PC, et al. Non-risk-adapted surveillance for stage I testicular cancer: critical review and summary. Eur Urol 2018;73:899-907.

9 Haugnes HS, Bosl GJ, Boer $\mathrm{H}$, et al. Long-Term and late effects of germ cell testicular cancer treatment and implications for follow-up. JCO 2012;30:3752-63.

10 Kier MG, Hansen MK, Lauritsen J, et al. Second malignant neoplasms and cause of death in patients with germ cell cancer: a Danish nationwide cohort study. JAMA Oncol 2016;2:1624-7.

11 Tandstad T, Ståhl O, Dahl O, et al. Treatment of stage I seminoma, with one course of adjuvant carboplatin or surveillance, risk-adapted recommendations implementing patient autonomy: a report from the Swedish and Norwegian testicular cancer Group (SWENOTECA). Ann Oncol 2016;27:1299-304.

12 Aparicio J, Maroto P, García del Muro X, et al. Prognostic factors for relapse in stage I seminoma: a new nomogram derived from three consecutive, risk-adapted studies from the Spanish germ cell cancer Group (SGCCG). Ann Oncol 2014;25:2173-8.

13 Boormans JL, Mayor de Castro J, Marconi L, et al. Testicular tumour size and rete testis invasion as prognostic factors for the risk of relapse of clinical stage I seminoma testis patients under surveillance: a systematic review by the testicular cancer guidelines panel. Eur Urol 2018;73:394-405.

14 Zengerling F, Kunath F, Jensen K, et al. Prognostic factors for tumor recurrence in patients with clinical stage I seminoma undergoing surveillance-A systematic review. Urol Oncol 2018;36:448-58.

15 Dieckmann K-P, Dralle-Filiz I, Matthies C, et al. Testicular seminoma clinical stage 1: treatment outcome on a routine care level. $J$ Cancer Res Clin Oncol 2016;142:1599-607.

16 Warde P, Specht L, Horwich A, et al. Prognostic factors for relapse in stage I seminoma managed by surveillance: a pooled analysis. JCO 2002;20:4448-52.

17 Chung P, Daugaard G, Tyldesley S, et al. Evaluation of a prognostic model for risk of relapse in stage I seminoma surveillance. Cancer Med 2015;4:155-60.

18 Groll RJ, Warde P, Jewett MAS. A comprehensive systematic review of testicular germ cell tumor surveillance. Crit Rev Oncol Hematol 2007;64:182-97.

19 Vergouwe Y, Steyerberg EW, Eijkemans MJC, et al. Predictors of occult metastasis in clinical stage I nonseminoma: a systematic review. JCO 2003;21:4092-9.

20 Berney DM, Algaba F, Amin M, et al. Handling and reporting of orchidectomy specimens with testicular cancer: areas of consensus and variation among 25 experts and 225 European pathologists. Histopathology 2015;67:313-24.

21 AHS L, Mead GM, Theaker JM. The value of central histopathological review of testicular tumours before treatment. BJU Int 1999;84:75-8.
22 Sharma P, Dhillon J, Agarwal G, et al. Disparities in interpretation of primary testicular germ cell tumor pathology. Am J Clin Pathol 2015;144:289-94.

23 Purshouse K, Watson RA, Church DN, et al. Value of supraregional multidisciplinary review for the contemporary management of testicular tumors. Clin Genitourin Cancer 2017;15:152-6.

24 Harari SE, Sassoon DJ, Priemer DS, et al. Testicular cancer: the usage of central review for pathology diagnosis of orchiectomy specimens. Urol Oncol 2017;35:605.e9-605.e16.

25 Mortensen MS, Bandak M, Kier MGG, et al. Surveillance versus adjuvant radiotherapy for patients with high-risk stage I seminoma Cancer 2017;123:1212-8.

26 Horwich A, Alsanjari N, A'Hern R, et al. Surveillance following orchidectomy for stage I testicular seminoma. Br J Cancer 1992:65:775-8.

27 Warde P, Gospodarowicz MK, Banerjee D, et al. Prognostic factors for relapse in stage I testicular seminoma treated with surveillance. Journal of Urology 1997;157:1705-10.

28 Jacobsen GK, Rørth M, Osterlind K, et al. Histopathological features in stage I non-seminomatous testicular germ cell tumours correlated to relapse. Danish testicular cancer Study Group. Apmis 1990;98:377-82

29 Gilbert DC, Al-Saadi R, Thway K, et al. Defining a new prognostic index for stage I nonseminomatous germ cell tumors using CXCL12 expression and proportion of embryonal carcinoma. Clinical Cancer Research 2016;22:1265-73.

30 Alexandre J, Fizazi K, Mahé C, et al. Stage I non-seminomatous germ-cell tumours of the testis: identification of a subgroup of patients with a very low risk of relapse. Eur $J$ Cancer 2001;37:576-82.

31 Kollmannsberger C, Moore C, Chi KN, et al. Non-risk-adapted surveillance for patients with stage I nonseminomatous testicular germ-cell tumors: diminishing treatment-related morbidity while maintaining efficacy. Annals of Oncology 2010;21:1296-301.

32 Daugaard G, Kier M, Bandak M, et al. The Danish testicular cancer database. Clin Epidemiol 2016;8:703-7.

33 Erichsen R, Lash TL, Hamilton-Dutoit SJ. Existing data sources for clinical epidemiology: the Danish national pathology registry and data bank. Clin Epidemiol 2010;2:51-6.

34 Bjerregaard B, Larsen OB. The Danish pathology register. Scand $J$ Public Health 2011;39:72-4.

35 Lynge E, Sandegaard JL, Rebolj M. The Danish national patient register. Scand J Public Health 2011;39:30-3.

36 Pedersen CB. The Danish civil registration system. Scand J Public Health 2011;39:22-5.

37 Frank L. Epidemiology. When an entire country is a cohort. Science 2000;287:2398-9.

38 Danish testicular cancer database annual report 2018 (in Danish), 2018. Available: https://www.sundhed.dk/content/cms/86/15686 dateca-aarsrapport-2018.pdf

39 Schmidt M, Schmidt SAJ, Sandegaard JL, et al. The Danish national patient registry: a review of content, data quality, and research potential. Clin Epidemiol 2015;7:449-90.

40 National Health IT. Sundhedsvæsenets Klassifikations system (SKS). Available: http://www.ssi.dk/sks

41 Verrill C, Yilmaz A, Srigley JR, et al. Reporting and staging of testicular germ cell tumors. Am J Surg Pathol 2017;41:e22-32.

42 Berney DM, Comperat E, Feldman DR, et al. Datasets for the reporting of neoplasia of the testis: recommendations from the International collaboration on cancer reporting. Histopathology 2019;74:171-83.

43 Humphrey P, Moch H, Reuter V, et al. World Health organization (WHO) classification of tumours of the urinary system and male genital organs. IARC Press: Lyon, 2016.

44 Ulbright TM, Tickoo SK, Berney DM, et al. Best practices recommendations in the application of immunohistochemistry in testicular tumors. Am J Surg Pathol 2014;38:e50-9.

45 Dansk Urologisk Cancer gruppe. Available: www.ducg.dk

46 Rubin DB. Multiple imputation after 18+ years. J Am Stat Assoc 1996;91:473-89.

47 Little RJA, Rubin DB. Statistical analysis with missing data. ed 2. New York: NY Wiley \& Sons, 2002.

48 HARRELL FE, Lee KL, Mark DB. Multivariable prognostic models: issues in developing models, evaluating assumptions and adequacy, and measuring and reducing errors. Stat Med 1996;15:361-87.

49 Hsieh FY, Lavori PW. Sample-size calculations for the COX proportional hazards regression model with nonbinary covariates. Control Clin Trials 2000;21:552-60.

50 Schoenfeld DA. Sample-Size formula for the Proportional-Hazards regression model. Biometrics 1983;39:499-503. 
Correction: Prognostic factors for relapse in patients with clinical stage I testicular cancer: protocol for a Danish nationwide cohort study

Wagner T, Toft BG, Engvad B, et al. Prognostic factors for relapse in patients with clinical stage I testicular cancer: protocol for a Danish nationwide cohort study. BMJ Open 2019;9:e033713. doi: 10.1136/bmjopen-2019-033713.

A section of 'Introduction' has been duplicated in the published version. The same has been removed and corrected.

Open access This is an open access article distributed in accordance with the Creative Commons Attribution Non Commercial (CC BY-NC 4.0) license, which permits others to distribute, remix, adapt, build upon this work non-commercially, and license their derivative works on different terms, provided the original work is properly cited, appropriate credit is given, any changes made indicated, and the use is non-commercial. See: http://creativecommons.org/licenses/by-nc/4.0/.

C Author(s) (or their employer(s)) 2019. Re-use permitted under CC BY-NC. No commercial re-use. See rights and permissions. Published by BMJ.

BMJ Open 2019;9:e033713corr1. doi:10.1136/bmjopen-2019-033713corr1

(A) Check for updates 